\title{
Prediction of standard penetration test (SPT) value in Izmir, Tur- key using radial basis neural network
}

\author{
Yusuf Erzin*, Yesim Tuskan \\ Department of Civil Engineering, Manisa Celal Bayar University, Manisa Turkey, \\ yusuf.erzin@cbu.edu.tr; yesim.tuskan@cbu.edu.tr \\ * Corresponding author \\ Recieved: $16^{\text {th }}$ October 2016 \\ Accepted: 26 ${ }^{\text {th }}$ April 2017 \\ DOI: $10.18466 /$ cbayarfbe.319912
}

\begin{abstract}
Site exploration, characterization and prediction of soil properties by in-situ test are key parts of a geotechnical preliminary process. In-situ testing is progressively essential in geotechnical engineering to recognize soil characteristics alongside. In this study, radial basis neural network (RBNN) model was developed for estimating standard penetration resistance $(S P T-N)$ value. In order to develop the RBNN model, 121 SPT-N values collected from 13 boreholes spread over an area of $17 \mathrm{~km}^{2}$ of Izmir was used. While developing the model, borehole location coordinates and soil component percentages were used as input parameters. The results obtained from the model were compared with those obtained from the field tests. To examine the accuracy of the RBNN model constructed, several performance indices, such as determination coefficient, relative root mean square error, and scaled percent error were calculated. The obtained indices make it clear that the RBNN model has a high prediction capacity to estimate SPT-N.
\end{abstract}

Keywords - Generalized regression neural network, In-situ test, Radial basis neural network, Standard penetration test

\section{Introduction}

The complex geotechnical behavior and uncertainty of soil effect are a challenge for a simplified geotechnical model [1, 2]. In the case of nonlinear modeling, phase of using traditional modeling techniques of multiple regression in predicting the standard penetration resistance $(S P T-N)$ in association with independent variables such as soil types and borehole coordinates cannot be performed and thus the development of a comprehensive model for the estimation of SPT-N is almost impossible for this technique [1, 2]. For site exploration, in situ tests are used to delineate soil stratigraphy and determine its properties for geotechnical analysis and design.

The penetration resistances are used to classify and characterize subsoils. Substantial data can be obtained economically in shorter time using in situ devices, such as the standard penetration test (SPT) and cone penetration test (CPT). Some geotechnical design parameters of the soil are associated with the SPT. In construction projects, it is common to use SPT for the preliminary soil investigation.

SPT is a commonly used method of investigating soil properties such as bearing capacity, liquefaction and site characterization. The test is applicable to a widely ranged soil conditions. With the advance of modern geotechnical engineering the actual driving energy of the SPT entering the rods was measured easily as described in ASTM D4633 by energy measurement devices. SPT-N was normalized to an overburden pressure of $100 \mathrm{kPa}$ as part of semi-empirical procedure using the correction factor $\left(\mathrm{C}_{\mathrm{N}}\right)$ proposed by Kayen et al. [3]. The $C_{N}$ value was limited to a maximum value of 1.70 as suggested by Youd et al. 
[4] and this factor commonly calculated from the following Eq.(1.1):

$$
C_{N}=\frac{2.2}{1.2+\frac{\sigma_{v o}^{\prime}}{P_{0}}}
$$

where, $\sigma_{v 0}^{\prime}$ is effective overburden pressure and $P_{0}$ is $100 \mathrm{kPa}$ [3]. Field SPT-N value was corrected for $\mathrm{C}_{\mathrm{N}}$ using Eq.(1.2) proposed by Peck et al. [5] for measured values used in GRNN model:

$$
N_{\text {cor }}=S P T N \times C_{N}
$$

The negative pore pressure of the SPT sampler into saturated sand and silts may result in higher shearing resistance. Therefore, $\mathrm{N}_{\text {cor }}$ values greater than 15 and under ground water level, obtained from equation (2) were corrected using the Eq.(1.3) [6]:

$$
N_{\text {cor }}^{\prime}=15+0.5 \times\left(N_{\text {cor }}-15\right)
$$

In the present study, radial basis neural network $(R B N N)$ model was developed for estimating standard penetration resistance $(S P T-N)$ value. In order to develop the RBNN model, a detailed study conducted for the examination of the geological and geotechnical behavior of Zeytindagi Formation soil Izmir-Manisa State Road [1, 7], including the SPT-N value of soils and their borehole location coordinates with soil percentages of different 121 data points, was used.

The descriptive statistics of the data are given in Table 1 . Moreover, the determination coefficient $\left(R^{2}\right)$ the relative root mean square error (RRMSE), and scaled relative error $\left(E_{r}\right)$ indices were utilized to estimate the performance of the RBNN model developed.

Table 1. Descriptive Statistics for Collected Field Data of SPT-N [1]

\begin{tabular}{clccc}
\hline & Min. & Max. & Mean & Std. Deviation \\
\hline X & 3 & 44 & 35.08 & 17.08 \\
Y & 3 & 44 & 11.85 & 17.07 \\
Z & 0.50 & 12 & 5.11 & 2.32 \\
Gravel (\%) & 0 & 67 & 13.28 & 17.61 \\
Sand (\%) & 3 & 72 & 32.18 & 16.18 \\
Silt (\%) & 3 & 66 & 32.44 & 16.49 \\
Clay (\%) & 0 & 67 & 22.27 & 16.61 \\
SPT-N & 1 & 50 & 19.45 & 14.56 \\
\hline
\end{tabular}

\section{Case Study Area: Gediz Basin}

In this work, a detailed study [1, 7] of the geological and geotechnical behavior of Zeytindagi Formation soil was used and given briefly as follows. The topography and geologic history of the Zeytindağ 1 Formation slope influences the behavior of the Manisa-Izmir State Road.

The roadway is located near the crest of an ancient valley slope and is situated below the top of a plain between Izmir and Bornova fault zone. Theses slopes consist of ancient landslides created by the unpredictable earthquake effects in the post glacial period. Gediz Basin is bordered in the north by the Bornova Fault and in the south by the İzmir Fault. Sedimentary rocks with ages ranging from Lower Miocene to middle Miocene are exposed in İzmir and its environs. The Miocene aged deposits in the test area were affected by two faults with the developed alluvium deposits.

Historical earthquakes and morphological traces of the faults show that the Bornova and İzmir faults are active faults $[1,7]$.

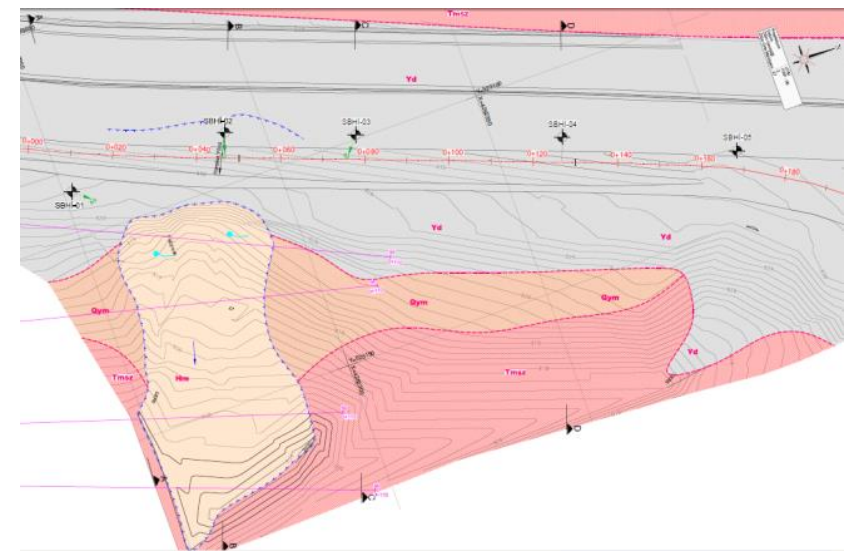

Figure 1. Geological setting, morphology and Location of the Gediz Basin area [7]

\section{Radial Basis Neural Network}

Artificial Neural Networks (ANNs) governs the learning of the connection between input and output variables in a way similar to the human brain, without preconditioned or optional assumptions [8]. The human brain resembles systems of learning, association, classification, making generalizations, estima- 
tion and optimization were provided by ANN as an information system [9]. The limitations of various numerical modeling techniques and fails of many mathematical models for highly non-linear behavior of soils are also considered to be complex, timeconsuming and not always practical for geotechnical approaches. In geotechnical engineering problems as with many areas of civil engineering, ANN has been used with great accuracy to predict and model the field tests.

Radial basis neural networks (RBNNs) are feedforwardtype ANNs, which have universal approximation properties [9]. RBNN utilizes a clustering process with different nonlinear activation functions that are locally tuned to cover a region of the input space [10]. This process is repeated until the prediction error is small enough, as defined by the spread factor. Then the testing phase is applied to show the capability of networks for data generalization.

RBF can be used to solve high-dimensional approximation problems. The training data was interpolated by the multi-dimensional space to fit the best curved surface [11]. RBNN are generally divided into three layers [12] as shown in Fig.2. Several origins called perception units were connected by the input layer, of the external environment [12]. A number of radial basis function units $\left(\mathrm{n}_{\mathrm{h}}\right)$ and bias $\left(\mathrm{b}_{\mathrm{k}}\right)$ were situated in the hidden layer of RBNNs [13].

The output layer is activated by the linear activation of the input layer [12]. Any iterative learning is required in radial basis networks. [13]. RBNN model is very faster than the well-known back-propagation neural network as a characteristic behavior. RBNN has also advantages over conventional models such higher reliability and smaller error foundings [14]. The overall block diagram of the RBNN in its adaptive form for SPT-N estimation is also depicted in Figure 2.

The radial basis function (RBF) is characterized by Gaussian function constituted by center $\left(\mathrm{v}_{\mathrm{j}}\right)$ and width $\left(r_{j}\right)$. The Euclidean distance of the RBF was measured in the hidden layer using following equation [13].

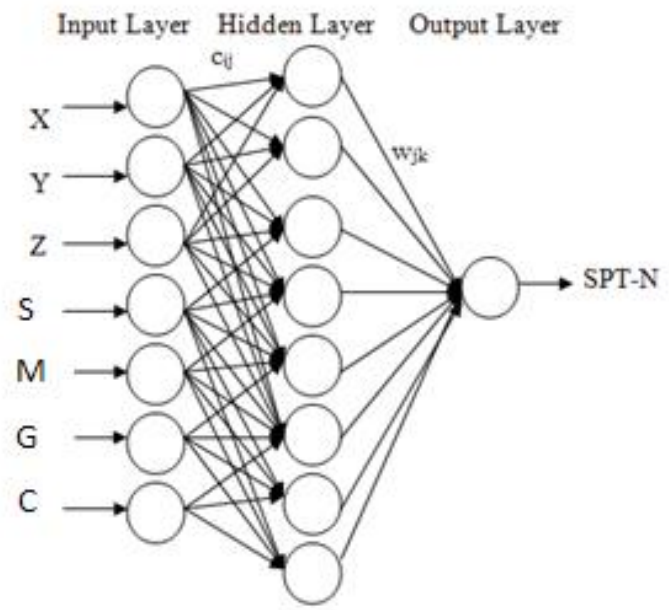

Figure 2. RBNN model architecture for SPT-N estimation

$$
\mathrm{h}_{\mathrm{j}}(x)=\exp \left(-\left\|x-v_{j}\right\|^{2} / r_{j}^{2}\right)
$$

where $h_{j}$ denotes the output of the $j$ th unit of RBF. The center and width of the RBF are shown by $c_{j}$ and $r_{j}$, respectively. The following equation is the output layer of the function [13].

$$
\mathrm{y}_{\mathrm{k}}(x)=\sum_{j=1}^{n_{k}} w_{k j} h_{j}(x)+b_{k}
$$

where $y_{k}$ is the $k_{t h}$ output unit for the input vector $x$, $W_{\mathrm{kj}}$ is the weight connection between the $\mathrm{k}_{\text {th }}$ output unit and the jth hidden layer unit, and $b_{k}$ is the bias.

The expected yk output parameter of the corresponding $x$, is updated by minimizing some measure of discrepancy between these parameters.

$$
\mathrm{y}_{\mathrm{k}}(x)=w_{0}+\sum_{j=1}^{c} w_{j} g\left(\left\|x-v_{j}\right\|\right)
$$

The function approximation can be extended as Eq.3.4 for $n_{0} \geq 1$.

$$
\begin{gathered}
\mathrm{y}_{\mathrm{i}}=\sum_{j=1}^{n_{k}} f\left(w_{i 0}+\sum_{j=1}^{c} w_{i j} g\left(\left\|x-v_{j}\right\|^{2}\right)\right), 1 \leq \mathrm{i} \leq \mathrm{n}_{\mathrm{o}} \\
\mathrm{g}\left(\mathrm{x}^{2}\right)=\phi(x)(8)
\end{gathered}
$$

Considering $\phi(x)$ as radial basis function, the response of the network is shown in Eq. (3.5).

$$
y_{i}=f\left(\sum_{j=0}^{c} w_{i j} h_{j}\right), 1 \leq \mathrm{i} \leq \mathrm{n}_{\mathrm{o}}
$$


hj represents the response of the radial basis function located at the jth unit to the input vector $x$, at that rate;

$$
\begin{aligned}
& \mathrm{h}_{\mathrm{j}}(x)=\phi\left(\left\|x-v_{j}\right\|\right) \\
& \mathrm{h}_{\mathrm{j}}(x)=g\left(\left\|x-v_{j}\right\|^{2}\right), 1 \leq j \leq c
\end{aligned}
$$

The RBNN is introduced with $x$ and is formed by the response of the radial basis function located at the $\mathrm{c}$, $1 \leq \mathrm{j} \leq \mathrm{c}$ in Eq.(3.6).The forward subset selection routine of training set was utilized in order to optimize the centers. A least-squares solution method was applied to adjust the connection weight between output layer and hidden layer following the selection of optimum values of centers of RBF. A successful utilization of an optimum spread value obtained the most definite simulation results to minimize model prediction error.

\section{Radial Basis Neural Network Model}

In order to develop the RBNN model, 121 SPT-N values collected from 13 boreholes spread over an area of $17 \mathrm{~km}^{2}$ of Izmir, Turkey [1, 7], including finegrained deposits of mostly silt and clay with weathered gravel and sand, was used. In the RBNN model, the percentages of sand (S), silt $(M)$, gravel $(G)$, and clay $(\mathrm{C})$ particle size of the present soil and $\mathrm{X}, \mathrm{Y}$, and $\mathrm{Z}$ coordinates of boreholes were used as input parameters and SPT-N used as one single output parameter.

The input-output data of the RBNN model were scaled to lie between 0 and 1, by using Eq. (4.1).

$$
x_{\text {norm }}=\frac{\left(x-x_{\min }\right)}{\left(x_{\max }-x_{\min }\right)}
$$

where, the normalized value is defined by $x_{\text {norm, }}$ the actual value is characterized by $x$, finally $x_{\max }$ and $x_{\min }$ are the maximum and the minimum values, respectively. The available data was then divided into two subsets as a common practice: A training set to construct the neural network model, and an independent testing set to prove the model performance in the deployed environment. In total, $80 \%$ of the data (i.e., 96 data sets), $20 \%$ (i.e., 25 data sets) were used for training and testing sets, respectively. Finally, the predicted SPT-N values from RBNN model was compared with the actual measured SPT-N values using the performance indices, namely, the coefficient of correlation, $R^{2}$, given by Eq. (4.2), the relative root mean square error, RRMSE, given by Eq. (4.3) to assess the performance of the RBNN model developed in this study.

$$
\begin{aligned}
R^{2}=1- & \frac{\sum_{i=1}^{N}\left(y_{i}-\hat{y}_{i}\right)^{2}}{\sum_{i=1}^{N}\left(y_{i}-\bar{y}\right)^{2}} \\
\text { RRMSE }= & \frac{\sqrt{\frac{1}{N} \sum_{i=1}^{N}\left(y_{i}-\hat{y}_{i}\right)^{2}}}{\frac{1}{N} \sum_{i=1}^{N}\left(y_{i}\right)^{2}}
\end{aligned}
$$

where $y$ is the measured value; $\hat{y}$ is the predicted value; ${ }^{y}$ is the mean of the measured data; and $N$ is the number of the sample.

Very few user decisions are required while using RBNN model. The selection of an appropriate smoothing factor is only required to train the inputs. For each input combination, the optimum spread for the RBNN model was determined according to the MAE criterion. In order to minimize model prediction error, the variation of spread parameter with mean absolute error (MAE) was examined, which is given in Fig.3. The spreads were found to vary between 0.01 and 0.04 . It appears from the figure that the RBNN has a minimum MAE value with the spread value of 0.04 .

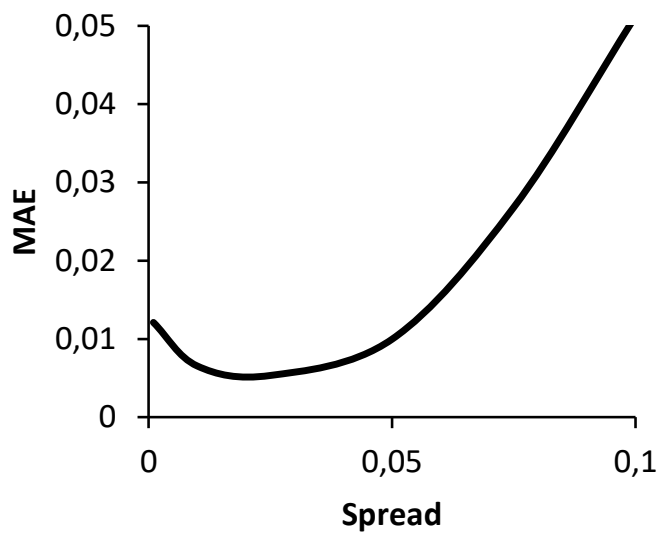

Figure 3. The effect of spread parameter on RBNN performance 


\section{Results and Discussion}

The comparison between the obtained standard penetration test number (SPT-N) values and the predicted SPT-N values from the RBNN model is shown in Figures 4 and 5 . It can be noted from these figures that predicted SPT-N values from the RBNN model are found to be in a perfect agreement with the measured SPT-N values, as $R^{2}$ of 0.9993 and 0.9848 for training and testing, respectively.

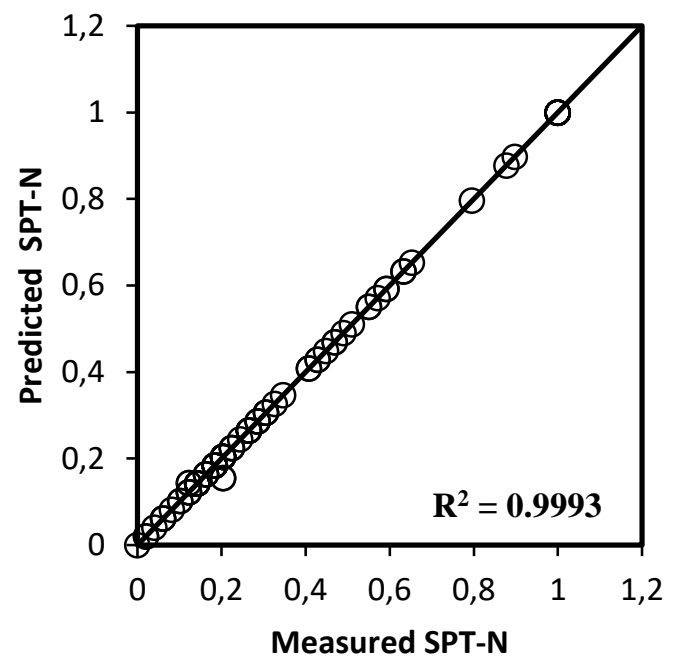

Figure 4. The comparison of the measured versus predicted SPT-N values for training samples of RBNN

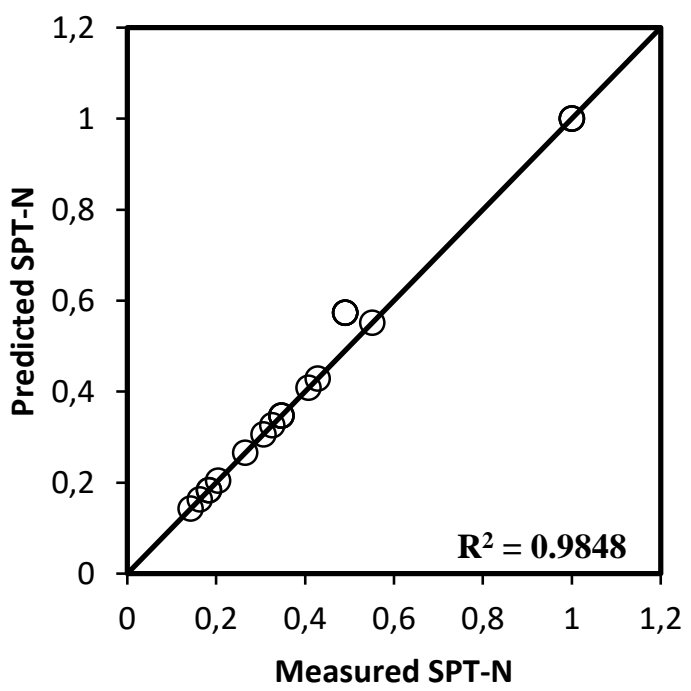

Figure 5. The comparison of the measured versus predicted SPT-N values for testing samples of RBNN.

Erzin and Tuskan [1] developed a generalized regression neural network (GRNN) model by using the same input and output parameters for the prediction of the SPT-N value. The measured standard penetration test number (SPT-N) values obtained from field test were compared with the predicted SPT-N values from the GRNN model in Figs. 6 and 7. It can be noticed from these figures that predicted SPT-N values from GRNN model are in good agreement with the obtained SPT-N values, as $R^{2}$ of 0.9738 and 0.9348 for training and testing, respectively.

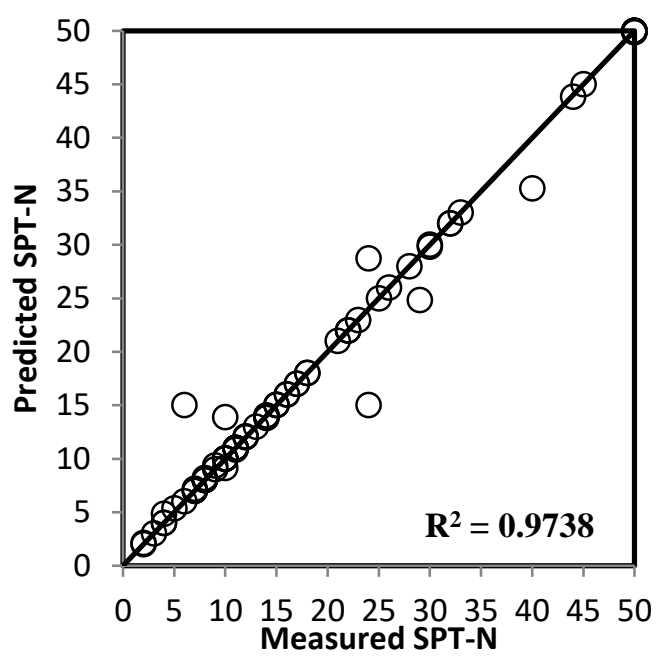

Figure 6. The comparison of the measured versus predicted SPT-N values for training samples of GRNN

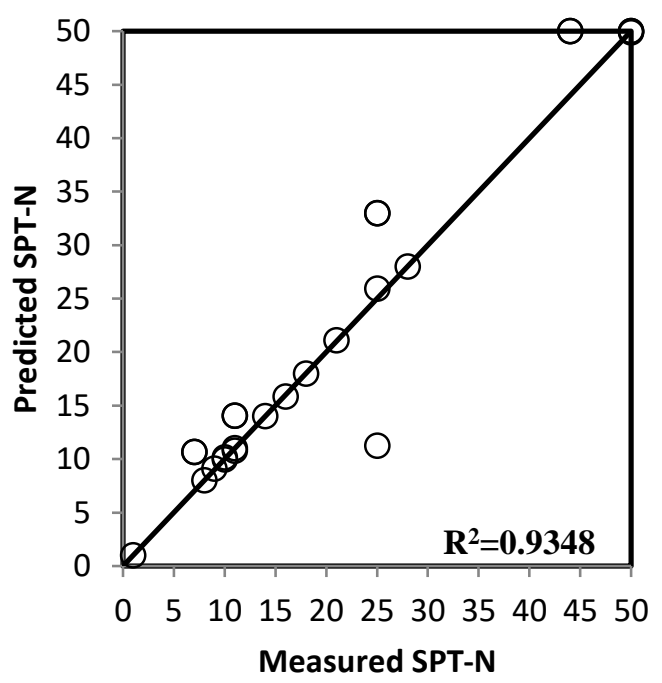

Figure 7. The comparison of the measured versus predicted SPT-N values for testing samples of GRNN

Moreover, different methods of evaluation of model performance have been utilized to demonstrate perfect predictability and reliability of the developed ANN models. 
Table 2 shows performance of the RBNN model developed in this study and GRNN model developed by Erzin and Tuskan [1]. The RBNN exhibited higher prediction performance than GRNN model based on the performance indices in Table 2.

Table 2. Performance indices ( $R^{2}$ and $\left.R R M S E\right)$ of the GRNN and RBNN models

\begin{tabular}{llll}
\hline Model & Data & $\begin{array}{l}R^{2} \\
(\%)\end{array}$ & RRMSE \\
\hline \multirow{2}{*}{ GRNN } & $\begin{array}{l}\text { Training } \\
\text { set }\end{array}$ & 97.38 & 0.04 \\
& $\begin{array}{l}\text { Testing } \\
\text { set }\end{array}$ & 93.48 & 0.08 \\
\hline \multirow{2}{*}{ RBNN } & Training & & \\
& set & 99.93 & 0.02 \\
& $\begin{array}{l}\text { Testing } \\
\text { set }\end{array}$ & 98.48 & 0.03 \\
\hline
\end{tabular}

A graphic representation of the comparative accuracy of the RBNN and GRNN models are shown by plotting the scaled relative error $\left(\mathrm{Er}_{\mathrm{r}}\right)$, given by Eq. (5.1), versus scaled cumulative frequency for the GRNN and RBNN models, as shown Figs. 8 and 9.

$$
\mathrm{E}_{\mathrm{r}}(\%)=\frac{S P T N_{p i}-S P T N_{m i}}{S P T N_{m i}} \times 100
$$

where SPTN $N_{\mathrm{pi}}$ and $\mathrm{SPTN}_{\mathrm{mi}}$ are the predicted and the measured standard penetration resistance.

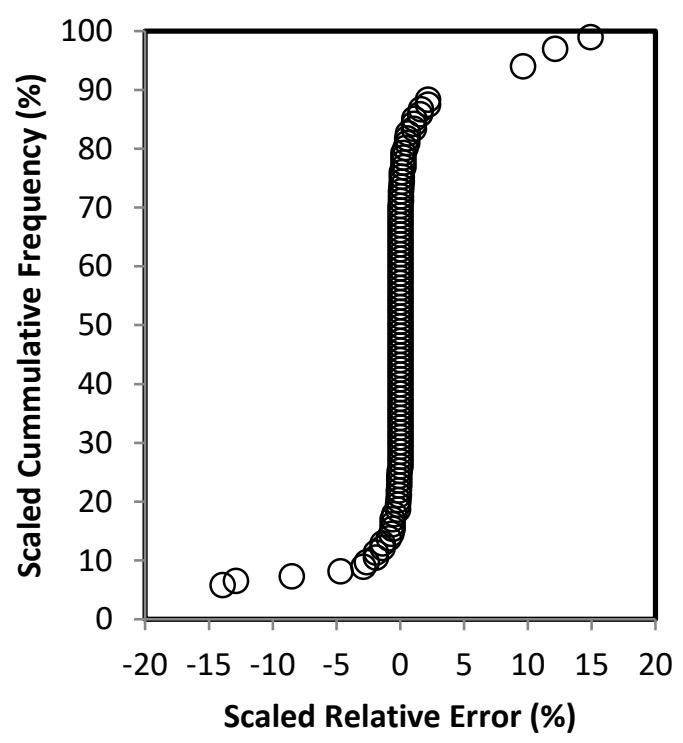

Figure 8. The scaled relative error versus scaled cumulative frequency for $R B N N$ model
It is seen from Fig. 8 that about $89 \%$ of SPT-N value predicted from the RBNN model fall into $\pm 5 \%$ of the $\mathrm{Er}_{\mathrm{r}}$ yielding a better estimate for the SPT-N value. It is observed from Fig. 9 that $82 \%$ of SPT-N value predicted from the GRNN model fall into $\pm 5 \%$. Wide ranges of prediction were observed by $R B N N$ model in comparasion to GRNN model.

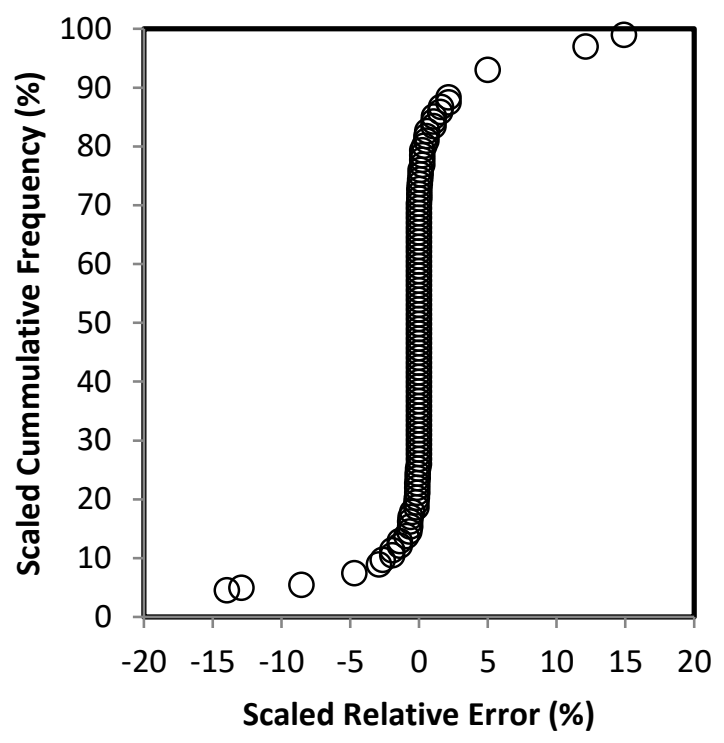

Figure 9. The scaled relative error versus scaled cumulative frequency for GRNN model

These results indicate that the $R B N N$ developed were superior to the GRNN model in predicting the standard penetration resistance (SPT-N).

\section{Conclusion}

In this study, the performance of the radial basis neural network $(R B N N)$ model to predict the standard penetration resistance (SPT-N) has been investigated and compared. For this purpose, a RBNN model was developed by using the data collected from 13 boreholes spread over an area of $17 \mathrm{~km}^{2}$ of Izmir. The SPT-N values estimated from the RBNN model were compared with the experimental results taken from the study area. The results indicated that the predicted values from the RBNN model are found to be very close to the measured values.

The prediction performance of the RBNN model developed in this study and the GRNN model developed by Erzin and Tuskan [1] by utilizing the same 
data used in this study was compared and validated in terms of determination coefficient $\left(R^{2}\right)$, the relative root mean square error (RRMSE), and scaled relative error $\left(E_{r}\right)$. The computed indices make it clear that the constructed $R B N N$ model was able to predict standard penetration resistance (SPT-N) quite efficiently and outperformed the GRNN models. Our results suggest that the $R B N N$ algorithm is more applicable compare to the GRNN algorithm in treatment such kind of nonlinear data sets. Thus, the developed RBNN model can be used satisfactorily to predict the SPT-N value from their soil gradation properties and borehole coordinates as a rapid inexpensive substitute for laboratory techniques. To minimize the uncertainties encountered during the soil engineering projects, $R B N N$ model could be utilized as a useful machine learning tool. Therefore, the usage of the RBNN may supply new approaches and methodologies, and minimize the potential inconsistency of correlations.

\section{References}

[1] Erzin, Y. ; Tuskan, Y. Prediction of standard penetration test (SPT) value in Izmir, Turkey using generalized regression neural network. International conference on agricultural, civil and environmental engineering (acee-16). 2016.

[2] Sarkar, G.; Siddiqua, S.; Banik, R.; Rokonuzzaman, Md. Prediction of soil type and standard penetration test (SPT) value in Khulna City, Bangladesh using general regression neural network", Q. Journal of Engineering Geology and Hydrogeology. 2015; 48,190-203.

[3] Kayen, R.E; Mitchell, J.K; Seed, H.B.; Lodge, A; Nishio, $\mathrm{S}$; Coutinho, R. Evaluation of SPT, CPT, and shear wavebased methods for liquefaction potential assessment using Loma Prieta data. NCEER .1992; 1, 177-204.

[4] Youd, T.L; Idriss I.M. Liquefaction resistance of soils: Summary report from the 1996 NCEER and 1998 NCEER/NSF workshops on evaluation of liquefaction resistance of soils. Journal of Geotechnical and Geoenvi- ronmental engineering, ASCE. 2001; 127(10), 817-833.

[5] Peck, R.B.; Hanson, W.E.; Thorburn, T.H. Foundation engineering, John Wiley \& Sons, New York, 1974.

[6] Terzaghi, K. ; Peck, R.B. Soil Mechanics in Engineering Practice. 2nd edn. Wiley, New York, 1968.

[7] Turkish Highways, Stability Problem-Geotechnical Report, Turkish Highways, Izmir. (Unpublished Work) 2015.

[8] McCulloch, W.S; Pitts, W. A Logical Calculus of the Ideas Immanent in Nervous Activity. Bulletin of Mathematical Biophysics. 1943; 5,115-133.

[9] Haykin, S. Neural Networks: A Comprehensive Foundation. Macmillan College Publishing Company, New York, USA, 1994.

[10] Tasdemir, Y; Kolay, E; Kayabali, K. Comparison of three artificial neural network approaches for estimating of slake durability index, Environmental Earth Science 2013; $68,23-31$.

[11] Zhongzhi, S. Neural Network. Higher Education Press, Beijing, 2009.

[12] Xu, Y; Zheng, J. Identification of Network- Traffic Based on Radial Basis Function Neural Network. ICICIS 2011, Part I, CCIS. 2011; 134, 173-179.

[13] Shahlaei, M; Madadkar-Sobhani, A; Fassihi, A; Saghaie, L; Arkan, E. QSAR study of some CCR5 antagonists as anti-HIV agents using radial basis function neural network and general regression neural network on the basis of principal components, Medical Chemistry Research. 2012; 21, 3246-3262.

[14] Moradkhani, H; Hsu, K; Gupta H.V.; Sorooshian, S. Improved stream flow forecasting using self-organizing radial basis function artificial neural networks, Journal of Hydrology. 2004; 295, 246-262. 